Article

\title{
Establishment of a Genetically Diverse, Disease-Resistant Acacia koa A. Gray Seed Orchard in Kokee, Kauai: Early Growth, Form, and Survival
}

\author{
Nicklos Dudley ${ }^{1, *}$, Tyler Jones ${ }^{1}$, Kaitlin Gerber ${ }^{2}$, Amy L. Ross-Davis ${ }^{3}{ }^{\mathbb{D}}$, \\ Richard A. Sniezko ${ }^{4}\left(\mathbb{D}\right.$, Phil Cannon ${ }^{5}$ and John Dobbs ${ }^{6}$ \\ 1 Hawaii Agriculture Research Center, Waipahu, HI 96797, USA; tjones@harc-hspa.com \\ 2 Department of Forest Engineering, Resources \& Management, Oregon State University, \\ Corvallis, OR 97333, USA; kagerber23@gmail.com \\ 3 Department of Forest Ecosystems \& Society, Oregon State University, Corvallis, OR 97333, USA; \\ rossdava@oregonstate.edu \\ 4 Dorena Genetic Resource Center, United States Department of Agriculture Forest Service, \\ Cottage Grove, OR 97424, USA; richard.sniezko@usda.gov \\ 5 United States Department of Agriculture Forest Service, Forest Health Protection, Vallejo, CA 94592, USA; \\ pcannon@fs.fed.us \\ 6 Department of Agricultural Biology, Colorado State University, Fort Collins, CO 80523, USA; \\ john.dobbs@colostate.edu \\ * Correspondence: ndudley@harc-hspa.com
}

Received: 30 October 2020; Accepted: 24 November 2020; Published: 28 November 2020

\begin{abstract}
Background and Objectives: Koa (Acacia koa A. Gray) is an economically, ecologically, and culturally valuable tree species endemic to Hawaii. A vascular wilt disease caused by the fungal pathogen Fusarium oxysporum f. sp. koae Gardner (FOXY) induces high rates of mortality in plantings and threatens native koa forests as well. Landowners are reluctant to consider koa for reforestation purposes in many areas due to the risk of mortality caused by FOXY. Producing seeds with genetic resistance to FOXY is vital to successful koa reforestation and restoration. The Hawaii Agriculture Research Center (HARC), with both public and private partners, operates a tree improvement program to develop wilt-resistant koa populations in Hawaii. The population genetics of koa is poorly understood and seed zones are evolving. Thus, HARC uses provisional seed zones based on genetic and biogeographic variables and has selected wilt-resistant koa populations that are locally found in Kokee, Kauai (eco-regions) of Hawaii. Materials and Methods: To make these selections, virulent FOXY isolates were used in previous seedling inoculation trials to evaluate resistance levels among koa families in greenhouse experiments, and the most resistant families were used in the field trial reported here. Results: In this trial, survival rates two years after planting varied by family, and ranged from $45 \%$ to $95 \%$, but all resistant families had greater survival rates than the susceptible control (25\%). The trial has been converted to a seed orchard. Conclusions: The higher survival rates of the families are encouraging and seeds coming from the orchard will improve the success of future restoration and reforestation efforts. Within these resistant families it was also possible to make some selections based on height, growth, diameter, and stem form. Thus, the establishment of a wilt-resistant seed orchard results in locally adapted, eco-region specific, disease-resistant koa seed that will allow for the restoration of this iconic species and provide plant material for commercial reforestation opportunities at the landscape level.
\end{abstract}

Keywords: Hawaii; koa; wilt-resistance; ecoregion; seed orchard; survival; growth performance; stem form; whole tree biomass; Fusarium oxysporum 


\section{Introduction}

Koa (Acacia koa A. Gray) is an overstorey tree species endemic to the Hawaiian archipelago that holds cultural, ecological, and economic significance. Koa is a dominant canopy tree, growing to heights over $30 \mathrm{~m}$ under ideal conditions, and is a keystone species in native forests where it provides suitable habitat for endangered native birds and epiphytic plants. Koa is also a nitrogen-fixing tree legume that forms both root and canopy nodules in association with Bradyrhizobium [1]. Significant koa forests are found on four of the major Hawaiian Islands (Hawaii, Maui, Oahu, and Kauai). This tree is of immense cultural importance to native Hawaiians. Its wood is used for a range of traditional applications. Most notably, it is the preferred wood for the construction of traditional Hawaiian voyaging canoes. Koa timber is a high-value hardwood, used for producing musical instruments, specialty furniture and other high value craft goods. The value of koa can exceed \$100 per board foot for highly figured wood. The very limited supply of commercial-quality trees is a significant limiting factor for the Hawaiian forest industry; in 2019 the total annual value of Hawaii's koa industry was estimated at $\$ 20$ to $\$ 30$ million [2].

Past planting practices for koa have often not prioritized keeping seeds from different ecoregions separate or maintaining genetic diversity. However, sustainable forestry will require emphasizing restoration or reforestation using genetically diverse seedlots, with wilt-resistant seed sources that are appropriate for the ecoregion in which they are planted. The Target Plant Concept, which serves as a theoretical framework aimed at aligning nursery and outplanting practices with successful seedling establishment, emphasizes the importance of choosing a proper seed source with high genetic quality to ensure seedlings are adapted to site conditions and factors limiting seedling survival [3,4]. Additionally, many land managers and conservation restoration groups are reluctant to plant koa originating from outside their ecoregion, which constitutes seed or planting zones for koa in Hawaii [5]. Therefore, knowledge about the range of genetic variations of koa will aid in the selection of the most appropriate seed sources for reforestation and restoration [6-8]. A. koa is an outcrossing tetraploid species with an extremely high degree of phenotypic variation and genetic diversity, although the population genetics of the species are poorly understood and breeding zones are provisional [5]. Due to the geographic isolation of islands across the Hawaiian archipelago, gene flow between islands is reduced and populations may have evolved separately. This has led to significant genetic differentiation among koa populations, which is broadly consistent with ecoregional delineations [9,10]. This ecoregional delineation is a conservative approach to establishing guidelines for deployment of koa seed sources in future planting. The Hawaii Agriculture Research Center (HARC) koa improvement program develops seed orchards of local koa populations within different geographic zones, referred to as ecoregions. In addition to selecting genetically diverse seedlots suitable for specific ecoregions, objectives include breeding for other characteristics as well. In the case of koa, there is interest in breeding for (1) resistance to koa wilt (Fusarium oxysporum f. sp. koae Gardner), (2) growth rate and good stem form, and (3) wood with high figure.

Koa wilt disease caused by the soil-dwelling fungus Fusarium oxysporum f. sp. koae (FOXY) spreads radially in soil, infecting susceptible plants through the root system, and can induce stand level mortality $[11,12]$. This vascular wilt pathogen restricts xylem water flow causing the phyllodes (modified petioles, which are leaf-like in appearance and function) to turn necrotic upon branch death, leading to crown die-off and eventual tree death [13]. The pathogen can cause up to $90 \%$ mortality in young plantings and can kill mature trees in native forests, which has discouraged restoration planting in many areas in the past. Fortunately, genetic variation appears to exist for resistance to FOXY [10].

Recent interest in koa reforestation and restoration in Hawaii and in the Kokee region of Kauai has generated a demand for disease-resistant seed. To help meet this demand, HARC, in collaboration with the US Forest Service and the State of Hawaii, Division of Forestry and Wildlife, has developed an on-going program to identify parent trees and progeny with resistance to koa wilt. HARC utilizes an inoculation test of seedling progeny of parent trees from natural stands to identify resistant parent trees and seedlings within the tested families [14,15]. In brief, highly virulent isolates are used to 
inoculate very young koa seedlings from open-pollinated families. This rapid and reliable screening method has allowed for the quick screening of hundreds of koa families collected from most of the 11 ecoregions across the State, including Kokee [5,9]. Through 2019, over 700 koa families have been tested and between 60 to 150 koa families per ecoregion have been screened for resistance, depending on the availability of seed from native forests.

Seed from parent trees showing high survival in the seedling inoculation trials was used to establish progeny tests on sites where FOXY is present. After several years the trials are converted to seed orchards, leaving the best individuals in each family (based on growth and form) to produce seed. The design of these Forward Selection-Seedling Seed Orchards follows guidelines provided in [16]. These field trials serve to validate the results of the seedling resistance testing as well as to monitor the durability and stability of resistance [17] and provide a progeny test to evaluate the form and growth rates of each family. The most resistant families and best individuals within a family row plot are retained after rogueing to establish a seed orchard to produce seedlots with genetic diversity, high levels of resistance to koa wilt, adaptation to local growing conditions, and an improved stem form and growth rate. Further, during rogueing operations, there is an opportunity to take wood samples and get an early estimate of the wood characteristics of each koa family in the test.

The wilt caused by FOXY is problematic throughout the Hawaiian Islands, especially below $900 \mathrm{~m}$ in elevation $[11,12,15]$, and is especially prevalent in the Kokee region of Kauai where it causes significant mortality. There is a great need for Fusarium resistant seed. Furthermore, there is also a great deal of interest in reforestation with koa following a recent wildfire, as this native species, when healthy, grows extremely well in this region. The Kokee wilt resistant orchard site was established in February 2017 and is part of a statewide network of ecoregion seed orchard locations. It included seedlings from 24 wilt-resistant families and one control (a composite seedlot from several highly susceptible koa parent trees). The goals of this work are as follows:

1. To evaluate the relative survival and growth performance of individual koa families under typical field conditions.

2. To provide significant quantities of genetically diverse disease-resistant koa seed for use in landscape-level reforestation and restoration within the Kokee ecoregion of Kauai.

3. To monitor both the durability of disease resistance and general survival, growth, and form of the seedlots used.

\section{Results}

After two years in the field, the susceptible local Kauai (KS) seedlot (collected from multiple susceptible mother trees) had only 25 percent survival. By comparison, all 24 wilt-resistant families (derived from single mother trees and selected based on survival from 110 families initially tested in a greenhouse disease screening study) displayed greater survival than the susceptible control (Figure 1 and Figure S1). Survival within individual seed sources (families or bulk seedlot) in year 1 ranged from $50 \%$ to $95 \%$ for the disease-resistant selections. In year 2, the range widened only slightly to $45 \%$ to $95 \%$ survival. Average survival of wilt resistant seed sources was $81 \%$ in 1 year and $75 \%$ in year 2, compared to $40 \%$ in year 1 and $25 \%$ in year 2 for the susceptible seed source. Notably, even after two years in the field, survival across families was generally higher (but significantly positively correlated) with survival in the greenhouse disease screening trial (Figure 2). The trials (after rogueing) will continue to be monitored for survival and growth performance.

In general, early growth performance was outstanding, with most seed sources obtaining mean heights and diameters at breast height of at least $2.5 \mathrm{~m}$ and $2 \mathrm{~cm}$, respectively, after the first year (Figure S2). At the end of the first year, seedlings of PR9 had the overall best form and potential timber selection at the family level. Seedlings of PH10 and PH5 had greater heights than many of the other families (Figure S2). Family PH10 also had a greater diameter than many of the other families (Figure S2). 


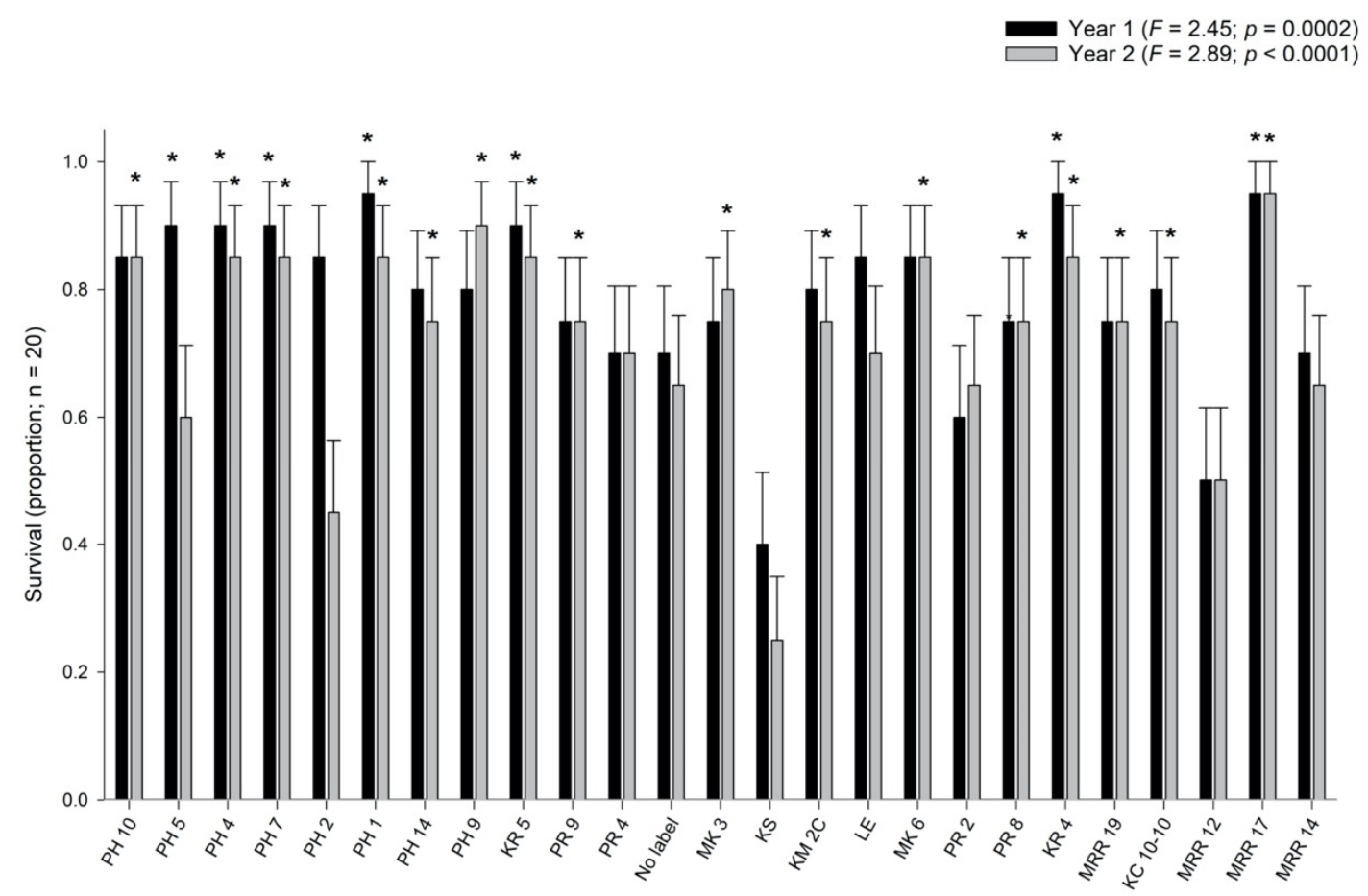

Figure 1. First and second year survival (mean \pm SE) across 25 Acacia koa A. Gray families after field establishment. Asterisks indicate a significant difference in survival among replicates within a family compared to Kauai susceptible (KS) control within a given year as determined by analysis of variance via generalized linear mixed models.

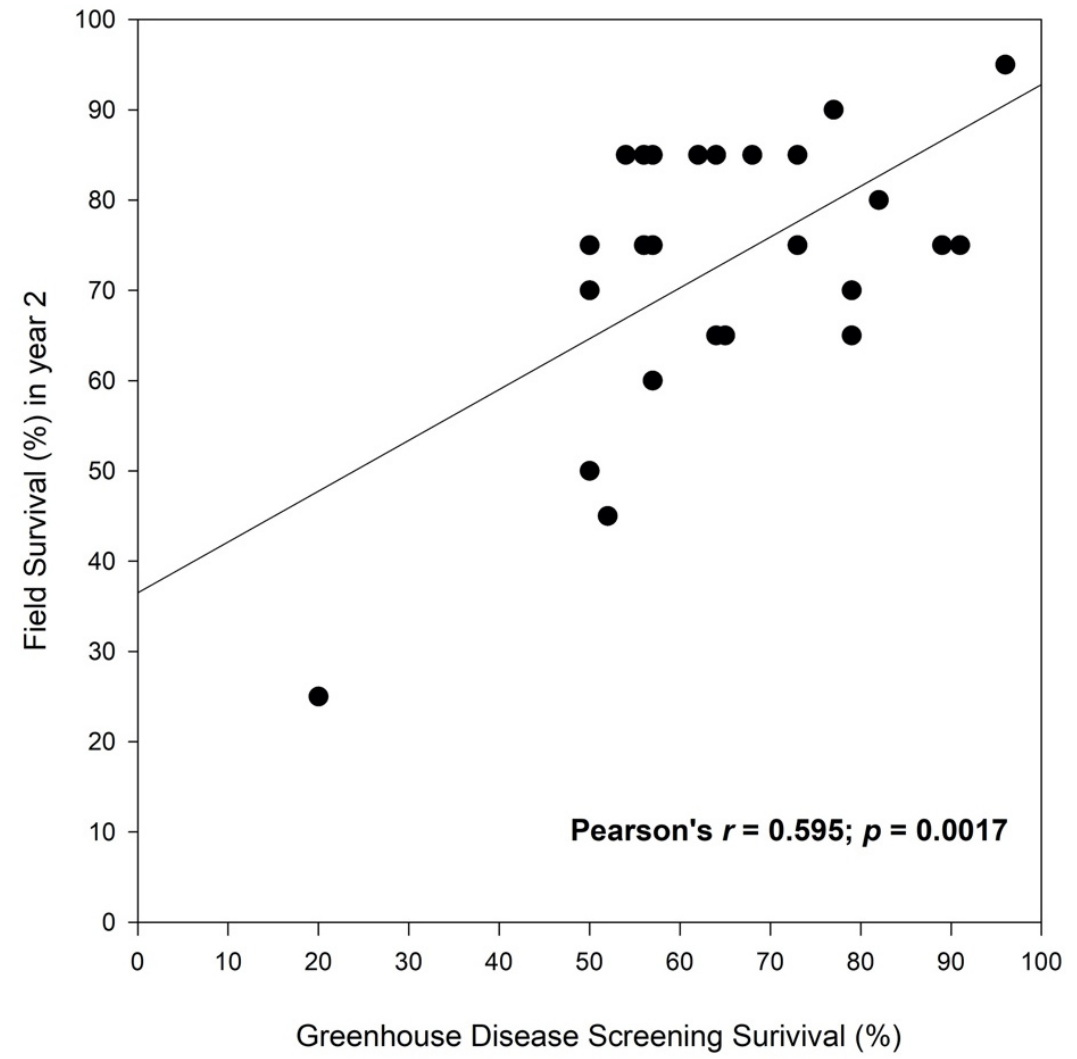

Figure 2. Correlation analysis used to illustrate the relationship between seedling survival during the greenhouse disease screening trial $(n=25)$ versus field survival in year $2(n=20)$ for 25 koa families. Each dot represents the overall survival of the particular family. 
At year 2, growth performance continued to be excellent with seedlings of most seed sources obtaining mean heights and diameters of at least $4 \mathrm{~m}$ and $6 \mathrm{~cm}$, respectively (Figure S3). Families varied in mean height from $3.2 \mathrm{~m}$ to $5.6 \mathrm{~m}$, and seedlings of the best family were $75 \%$ taller than those of the shortest family. At year 2, seedlings of PH4 had superior form, with the best timber potential at the family level. Seedlings of PH10 continued to be the largest overall in the trial in terms of height and among the largest in terms of diameter.

At year 3, growth performance continued to be excellent with an overall mean height of $5.5 \mathrm{~m}$ and diameter of $10.7 \mathrm{~cm}$ (Figure 3). Seedlings of PH4 as well as those of PH7 continued to show superior form in year 3, with the best timber potential at the family level. Seedlings of PH10 and PH4 continued to be the largest overall in the trial in terms of both height and diameter.
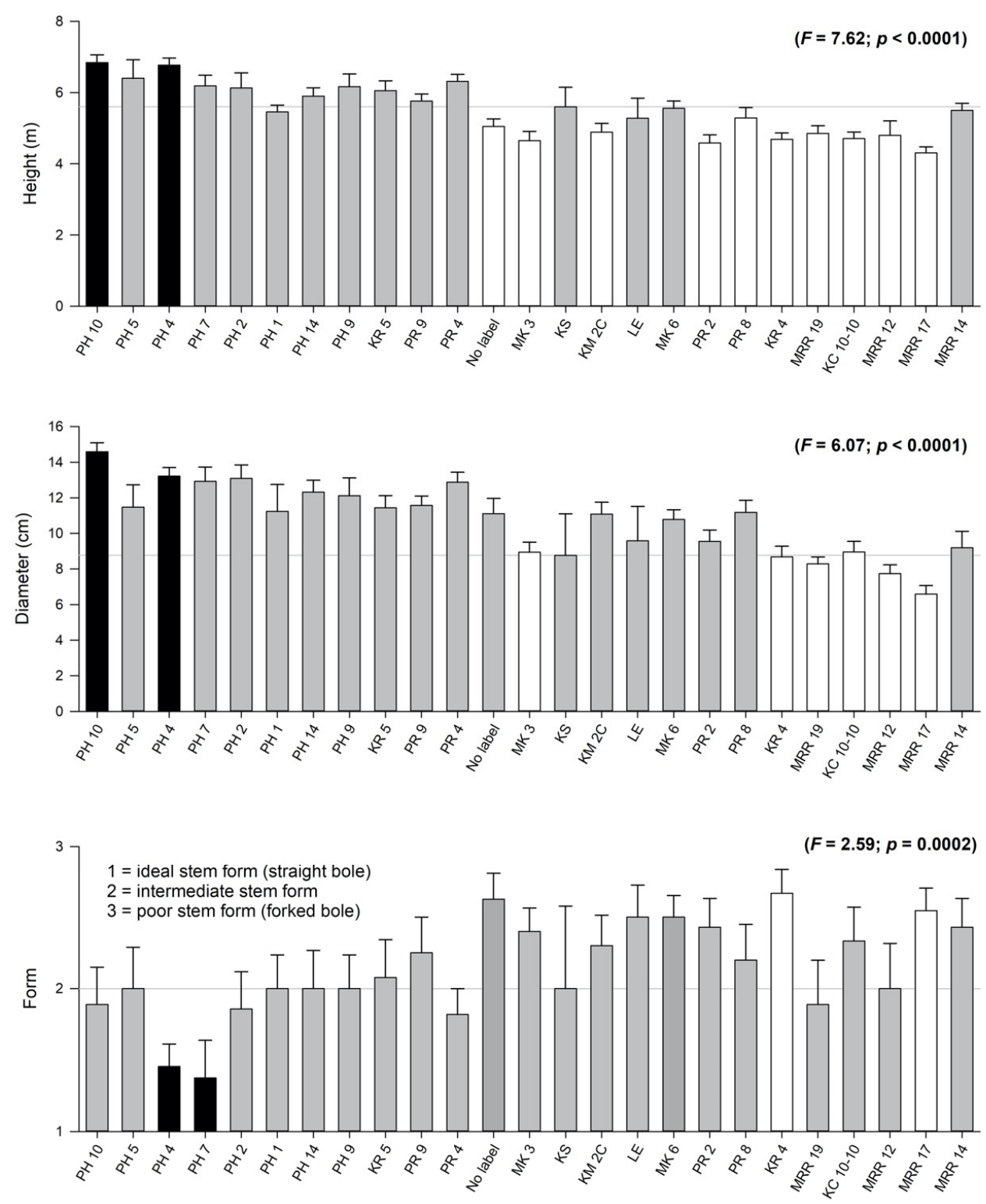

Figure 3. Height, diameter, and stem form of individual $A$. koa A. Gray families (mean \pm SE; $n=20$ ) three years after outplanting. Families represented by black bars had statistically significantly greater heights and diameters and superior form compared to those represented by white bars as determined by analysis of variance via generalized linear mixed models. KS is the susceptible control. 
Growth from year 1 to 2 varied among families (Figure S4). Seedlings of PH10, PH4, and PR4 had greater height growth (mean $\geq 1.98 \mathrm{~m}$ ) compared to those of many other families while those of PH10 and PH7 showed greater diameter growth (mean $\geq 4.66 \mathrm{~cm}$ ). From year 2 to 3, growth did not differ significantly among families (Figure S5).

At year 1, the overall mean whole-tree dry mass was $1.27 \mathrm{~kg}$ and ranged from $0.26 \pm 0.05 \mathrm{~kg}$ to $2.35 \pm 0.25 \mathrm{~kg}$ among families (Figure S6). PH10 seedlings had significantly greater whole-tree dry mass (mean $=2.35 \mathrm{~kg}$ ) than those of PR8, KM2C, MK families, LE, KR4, MRR families, and KC 10-10 (mean $\leq 1.28 \mathrm{~kg}$ ). Overall mean whole-tree dry mass increased to $8.84 \mathrm{~kg}$ in year 2, ranging from $1.53 \pm 0.28 \mathrm{~kg}$ to $16.37 \pm 1.35 \mathrm{~kg}$ among families. In year 2 , seedlings of PH10 and PH7 had significantly greater dry mass (mean $\geq 14.54 \mathrm{~kg}$ ) than those of PR2, MK families, KR4, MRR families, and KC 10-10 (mean $\leq 7.87 \mathrm{~kg}$ ). Overall mean whole-tree dry mass increased to $30.06 \mathrm{~kg}$ in year 3, ranging from $8.91 \pm 1.79 \mathrm{~kg}$ to $55.53 \pm 4.13 \mathrm{~kg}$ among families. Seedlings of PH10 continued to have significantly greater whole-tree dry mass (mean $=55.53 \mathrm{~kg}$ ) than those of PR2, PR8, MK families, KM2C, KS, LE, KR4, MRR families, and KC 10-10 (mean $\leq 31.46 \mathrm{~kg}$ ).

\section{Discussion}

Breeding trees to improve growth and for resistance to damaging diseases and insects has been used with success for many decades $[7,8,18]$. This is a key management action that can be implemented when the primary role of a species is undermined by a disease or insect. The role of classical selective breeding for resistance has been under-utilized, but there is now more recognition that it may be the only way to restore some species affected by a deadly disease or insect [19]. Koa's significance to the ecology, economy, and culture of Hawaii mandates efforts to identify and conserve wilt-resistant koa populations while maintaining genetic differentiation within the species. Developing koa planting stock that is resistant to the wilt-causing fungus Fusarium oxysporum $\mathrm{f}$. sp. koae is a critical step to meet the overall objectives of conserving Hawaii's remaining koa forests, restoring koa to its native range, and ensuring a sustainable supply of koa timber for future generations. Using classical selective breeding, the first confirmed wilt resistant koa genotypes have been identified in both seedling greenhouse assays [10,14] and in a field trial. The availability of this resistant stock reduces risk and uncertainty associated with growing koa in plantations and helps ensure that future koa populations are genetically diverse, robust, and adaptable to future threats and climate change.

In tree breeding, the objective is usually to develop populations of trees that have resistance, not one or two varieties or cultivars, as is often the case in crop breeding. This approach retains genetic diversity within the production population of long-lived trees, which will face many biotic and abiotic challenges. The rapid disease screening methods developed during the early phases of this project give the wilt-resistant koa program the ability to quickly segregate target populations into susceptible and resistant parent trees to develop genetically diverse genotypes with resistance to koa wilt. However, the true test of resistance comes in field plantings over time. The results of the trial reported herein are very encouraging. Although data indicate that field mortality is not yet fully expressed (likely due to a combination of environmental variability, escapes, uncontrolled inoculation, and possibly, tree age), our initial analysis shows that the ratings from the seedling inoculation trials were effective and survival rates of all the wilt-resistant families were substantially higher than those of the susceptible control (Figures 1 and 2).

For koa to be useful economically, the trees established must have desirable traits in addition to disease resistance. In the trial reported herein, several individual families displayed outstanding early growth and appear promising for potential commercial selection, particularly families PH10 and PH4, and families PH7 and PH4 ranked highest for stem form. Individual trees with better form have been selected within each family and the remaining $50 \%$ of the trees within each plot were removed at first thinning. The first thinning was implemented when the canopies of the majority of trees in the stand began to interlock. Owing to outstanding overall stand growth and initial spacing, the thinning occurred 30 months after planting. Continued monitoring of field plantings such as this 
one will allow further examination of the durability of resistance and selection of other traits such as growth performance, tree stem form and wood quality. Additional plantings elsewhere will provide information on the stability of resistance and ultimately its usability [17].

Due to the land use history in Hawaii as well as the economic and ecological importance of koa, it could play a much more important role in future forestry efforts, but only if resistant stock is available. The objective of establishing a wilt-resistant koa seed orchard comprised of locally sourced germplasm at the Kokee site is to provide a reliable source of improved seed for reforestation and restoration at a landscape level and form the foundation for a disease improvement program [18]. In the northwestern eco-region of Kauai, this is a high priority, as well as in other regions across the State. Using seed sources that are genetically well-adapted to the area to be planted, while also retaining genetic diversity within the seed source and incorporating wilt resistance, will be essential for maximizing the chance of successful restoration and reforestation. Selection for additional traits (of economic importance) can also be made, while retaining adaptability, genetic diversity and wilt resistance. Integrating this approach with nursery production and silvicultural practices highlights the cohesion that the Target Plant Concept brings to enhancing reforestation success [20].

The method used here has also been utilized elsewhere in Hawaii to ensure a reliable supply of genetically diverse, wilt-resistant koa seed that is appropriate for each ecoregion. The first orchards are just beginning to yield seed for planting. Additional seed orchard sites are planned for other parts of Kauai and in other eco-regions across the State that are currently under-represented. This first trial serves as a prototype upon which the other trials and orchards are being modelled. It also serves as a demonstration to land managers interested in koa reforestation and restoration. The result of this endeavor is the production of locally adapted, eco-region specific koa seed that will approximate the wide range of genetic diversity found in natural populations and allow for the restoration of this iconic species. It should also provide germplasm for commercial reforestation opportunities in many locations throughout the State.

The availability of resistant seed of koa has been a limiting factor for land managers. However, with this planting and the ensuing plantings and the level of resistance demonstrated, the future of koa is looking more encouraging. It is envisioned that these efforts will include further development of a distribution and seed-banking network for the release of improved koa seed for non-industrial and forest landowners and managers on Kauai and across the State. This will allow for the efficient distribution of improved (locally adapted, genetically diverse, disease-resistant) koa seed, which reduces risk and increases confidence in future reforestation and restoration efforts.

The results of this work have initiated the process of identifying locally adapted trees that will aid in the restoration of lands previously inhabited by koa and for continued commercial harvest. The first field results of koa wilt-resistant seedlots provide us with cautious optimism that restoration and reforestation with koa will no longer be impeded by the ubiquitous koa wilt pathogen. The orchards and subsequent field plantings can be monitored for any signs of maladaptation due to a changing climate. Future seed orchards are planned and changes (e.g., genetic composition) can be undertaken accordingly. Finally, this work adds to the short list of successful tree resistance programs and helps provide a roadmap for future programs world-wide. In particular, it provides a model for directly addressing the impact of newly emerging forest pathogens in Hawaii, including both Ceratocystis huliohia Barnes, Harrin. \& Keith (the causal agent of Ohia canker) and C. lukuohia Barnes, Harrin. \& Keith (the causal agent of Ohia wilt) on Ohia (Metrosideros polymorpha Gaudich.), the most common native forest tree in Hawaii and one of the most important ecological and cultural keystone species in Hawaiian forests [21].

\section{Materials and Methods}

\subsection{Seed Collection and Disease Screening}

Seeds from 110 mother trees in the Kokee region of Kauai were collected between 2010 and 2013 using the methods described in [5]. Greenhouse disease screening, which tested seedlings 
for resistance, was conducted to determine which koa seed families would be included in the seed orchard [10,14]. From this initial screening trial, a total of 24 seed sources that exhibited survival greater than $50 \%$ (mean across sources $=67 \%$, maximum $=96 \%$ ), were selected for inclusion in the seed orchard (Figure 4).

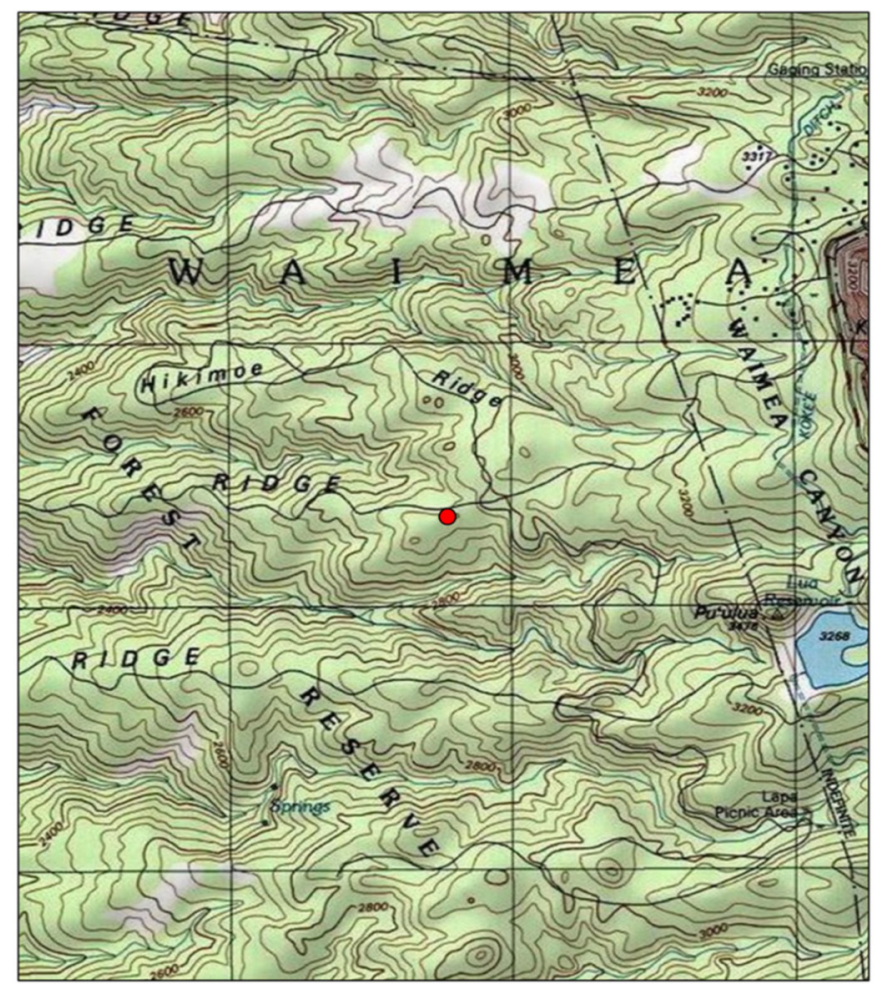

\section{Wilt Resistance Trial}

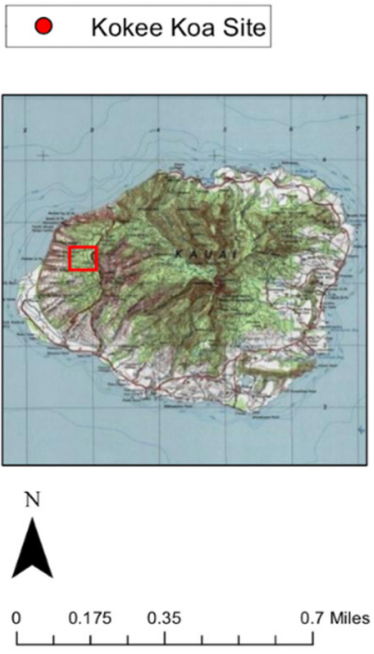

Figure 4. The wilt resistance trial (red dot) located on Polihale Ridge Road in Kokee on the west side of Kauai, HI, USA (inset map).

Treatments were coded to match the location of mother trees. The majority of seeds were collected from wild native populations in the local Kokee, Kauai ecoregion and were coded for specific locations as follows: Miloli'i Ridge (MRR), Makaha Ridge (MK), Polihale Ridge (PR), Kokee Museum (KM), Kitano Reservoir (KR), Camp 10 Rd (KC10), and Lapa Exclosure (LE). Seeds sourced from a koa grove directly adjacent to the established seed orchard were coded as Polihale exclosure (PH). Kauai susceptible (KS) bulk seed was used as a check lot to provide a baseline of a known susceptible koa seedlot. This seedlot had a $20 \%$ survival in the above-mentioned greenhouse disease screening. All treatments were half-sib families except the bulked susceptible koa seedlot.

\subsection{Site Preparation, Planting, and Maintenance}

A modified version of a randomized row-plot design was used. Plot locations were modified in each replication to maximize distance between plots of the same family. There were 4 replicates of 5-tree family plots, which included 20 seedlings per family planted in the experiment at a spacing of $2 \mathrm{~m} \times 3 \mathrm{~m}$. A bulldozer was used to move the vegetation off site. The site received a pre-planting herbicide application on November 2016, which consisted of glyphosate (RangerPro ${ }^{\circledR} 41 \%$ ) applied at a rate of $3.4 \mathrm{~kg} / \mathrm{ha}$ (Monsanto Company, St. Louis, MI, USA). The site was also spot sprayed one week prior to planting using a $2 \%$ solution of the same herbicide. In addition, the site was fenced for protection from ungulate browsing, primarily from the non-native black-tailed deer (Odocoileus hemionus coloumbianus Rafinesque).

Seedlings were initially grown for approximately 3 months in Ray Leach Cone-tainers SC-10 (Stuewe \& Sons Inc., Tangent, OR, USA) at HARC Maunawili Research Station, Oahu, HI, USA 
(21.352054, -157.760598) using Sunshine ${ }^{\circledR} \# 4$ growing media (SunGro ${ }^{\circledR}$ Horticulture, Agawam, MA, USA) and 6 g Osmocote ${ }^{\circledR}$ 14-14-14 (Scotts-Miracle-gro, Maryville, OH, USA) per seedling, supplemented with a foliar fertilization once per week at a rate of $1 \mathrm{~mL} / \mathrm{L}$ of Gaviota 62 12-24-24 (Gaviota Brand, BEI, Honolulu, HI, USA) before they were transported to Kauai to be planted in February 2017 (Figure A1). Seedlings were kept in buckets of water to keep roots moist while a $10 \mathrm{~cm}$ soil auger was used to create $0.3 \mathrm{~m}$-deep holes. Approximately $100 \mathrm{~g}$ of 0-45-0 phosphate fertilizer (Gaviota Brand, BEI, Honolulu, HI, USA) was incorporated into the bottom of each planting hole before planting. Seedlings were planted such that the top of the root plug was covered with soil ensuring the stem was not buried. Just after planting, approximately $170 \mathrm{~g}$ of gypsum (Gaviota Brand, BEI, Honolulu, HI, USA) was applied evenly to the soil surface in a $1 \mathrm{~m}$-diameter circle around each seedling and watered-in with $250 \mathrm{~mL}$ per seedling. One month after planting, approximately $115 \mathrm{~g}$ of 15-15-15 fertilizer (Gaviota Brand, BEI, Honolulu, HI, USA) was applied evenly to the soil surface in a $1 \mathrm{~m}$-diameter circle around each seedling.

The site was spot treated quarterly using a $2 \%$ solution of glyphosate herbicide as previously described, as well as supplemental hand ring weeding around the base of individual trees as needed. Primary weeds targeted for control included yellow pine (Pinus taeda L.), slash pine (Pinus elliottii Engelm.), Eucalyptus (Eucalyptus robusta Sm.), guava (Psidium guajava L.), California grass (Urochloa mutica (Forsk.) T.Q. Nguyen), molasses grass (Melinis minutiflora P.Beauv.) and blackberry (Rubus argutus Link). In November 2017, the lower branches of the koa saplings were pruned to a height of $1.5 \mathrm{~m}$ using hand shears to remove lateral branches to improve access and increase the ease of herbicide application. The total amount of foliage removed did not exceed $25 \%$ to avoid impacting tree growth and vigor.

Due to the exceptional growth rate at the site (Figures A2-A4), the tree canopies were starting to interlock and tree to tree competition was increasing, thus a prescribed thin was initiated in September 2019 and removed approximately 50\% of the trees in the stand. Thinning criteria was based on stem form, overall tree vigor, and if the tree was symptomatic for koa rust (causal agent: Atelocauda digitata (G.Winter) Cummins \& Y.Hiratsuka). There was a second sanitation thin in April 2020 for residual koa rust at the site. Excluding the susceptible control (KS), for which only 3 trees remained alive at year 3, the average number of trees remaining post-thinning per family was 9 and this ranged from a minimum of 5 to a maximum of 13 (Table S1).

\subsection{Data Collection and Analysis}

To assess field performance, height, dbh, stem form, and survival were measured 1-year (April 2018), 2-years (April 2019), and 3-years (June 2020) after planting. Stem form was assessed visually, scoring trees as " 1 " for better than average stem form (straight-bole), "2" for average stem form, and " 3 " for poor stem form (multi-branching bole). Data was collected 14 months, 26 months, and 38 months after planting and represent Year 1, 2, and 3 data, respectively.

\subsection{Whole Tree Biomass}

Aboveground dry biomass (kg) was calculated for whole trees (WTB) using allometric equations

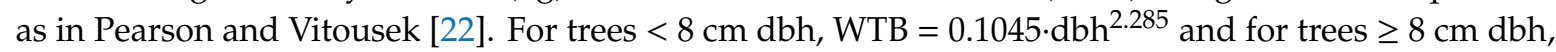
$\mathrm{WTB}=0.142 \cdot \mathrm{dbh}^{2.221}$. In year 1 , all trees had a dbh $<8 \mathrm{~cm}$. In year 2 , a total 275 trees had a dbh $<8 \mathrm{~cm}$ and 90 had $\mathrm{dbh} \geq 8 \mathrm{~cm}$. In year 3 , a total 36 trees had a dbh $<8 \mathrm{~cm}$ and $182 \mathrm{had} \mathrm{dbh} \geq 8 \mathrm{~cm}$.

\subsection{Statistical Analysis}

Data were analyzed using SAS software (version 9.4; SAS Institute, Cary, NC, USA) via PROC GLIMMIX. Models included the main effect of the koa family (seed source) with replicate included as a random effect. Comparisons among koa families were evaluated at $\alpha=0.05$ and adjusted for multiple comparisons (see Table S2 for pair-wise comparisons). SigmaPlot (version 14; Systat Software, Inc., San Jose, CA, USA) was used for data visualization. 


\section{Conclusions}

Significant differences in mortality among families in young koa field trials indicate that selecting the appropriate seedling material with disease resistance is a powerful tool for outplanting success. Early results have been encouraging, with top families showing high levels of survival. All wilt-resistant families displayed greater survival compared to the susceptible control. Further, growth performance was optimized by the appropriate silvicultural treatments (e.g., vegetation management and fertilization) applied in a timely manner. Once families with high survival are identified, the opportunity to select for other desirable traits, such as growth rate and biomass accumulation, stem form, and wood quality becomes possible, and the trial here has been rogued accordingly. The Kokee site will serve as a source of disease-resistant germplasm for koa reforestation and restoration efforts in the Northwestern region of Kauai and offers the potential to scale projects to the landscape level. The first wilt-resistant seed was harvested in August of 2019 and will be deployed in on-going reforestation efforts in Kokee, Kauai. This site is one of several seedling seed orchards across the State using families selected from disease screening trials. It is part of a statewide network of wilt-resistant seed orchards that HARC manages in collaboration with our private and public partners. Finally, the result of this endeavor is locally adapted, genetically diverse, wilt-resistant, eco-region specific koa seed that allows for the restoration of this iconic species and provides material for commercial reforestation opportunities. As demonstrated, a well-structured tree improvement program is vital to achieve the objectives of the target seedling concept, as healthy seedlings are essential for future forests.

Supplementary Materials: The following are available online at http://www.mdpi.com/1999-4907/11/12/1276/s1. Table S1: The number of living koa trees in each of the four replicates for each of the 25 families included in the wilt resistance field trial. (Note: $n=5$ seedlings initially planted in each replicate for each family.). Table S2: Differences of source least squares means for all pairwise comparisons across all variables measured in years 1,2 , and 3. Figure S1: Map of wilt resistant koa seed orchard consisting of 5 trees for each of 25 families planted in 4 replicates. Red blocks indicate mortality and the susceptible family is outlined in yellow. Figure S2: Height, diameter, and stem form of individual A. koa A. Gray families (mean \pm SE; $n=20$ ) one year after outplanting. Families represented by black bars had statistically significantly greater heights and diameters and superior form compared to those represented by white bars as determined by analysis of variance via generalized linear mixed models. KS is the susceptible control. Figure S3: Height, diameter, and stem form of individual A. koa A. Gray families (mean $\pm \mathrm{SE} ; n=20$ ) two years after outplanting. Families represented by black bars had statistically significantly greater heights and diameters and superior form compared to those represented by white bars as determined by analysis of variance via generalized linear mixed models. KS is the susceptible control. Figure S4: Height growth and diameter growth of individual $A$. koa A. Gray families (mean \pm SE) from year 1 to year 2 . Families represented by black bars had statistically significantly greater heights and diameters and superior form compared to those represented by white bars as determined by analysis of variance via generalized linear mixed models. KS is the susceptible control. Figure S5: Height growth and diameter growth of individual A. koa A. Gray families (mean $\pm \mathrm{SE}$ ) from year 2 to year 3 . KS is the susceptible control. Figure S6: Whole tree dry mass by individual A. koa A. Gray families (mean \pm SE) at years 1, 2, and 3. Families represented by black bars had statistically significantly greater whole tree dry mass compared to those represented by white bars as determined by analysis of variance via generalized linear mixed models. KS is the susceptible control.

Author Contributions: Conceptualization-N.D., T.J., R.A.S., P.C.; Methodology-N.D., T.J., R.A.S., P.C.; Software-N.D., T.J., K.G.; Validation-N.D., T.J., K.G., R.A.S., P.C., J.D.; Formal Analysis-N.D., T.J., K.G., A.L.R.-D., R.A.S., P.C., J.D.; Data Curation-N.D., T.J., K.G., J.D.; Writing-Original Draft Preparation-N.D., K.G.; Writing-Review \& Editing-A.L.R.-D., R.A.S., P.C., J.D., T.J.; Visualization-A.L.R.-D., N.D., T.J., K.G., R.A.S., P.C., J.D.; Supervision-P.C., N.D.; Project Administration-N.D., P.C.; Funding Acquisition-N.D., T.J., P.C. All authors have read and agreed to the published version of the manuscript.

Funding: This research was funded by US Forest Service R-5 Forest Health Protection grant number 2015-20.

Acknowledgments: The work was also supported by State of Hawaii, Department of Land and Natural Resources, Division of Forestry and Wildlife (Kauai Branch). We are grateful to Anthony S. Davis for an invitation to prepare this manuscript in support of a special issue on the Target Plant Concept, and to Carson Alberg for his contributions on the field site. Finally, we acknowledge and thank Aileen Yeh, Susan Scheck, Michael Kaufman, Adam Gutowski and Keith Adams for their contributions and support.

Conflicts of Interest: The authors declare no conflict of interest. 


\section{Appendix A}

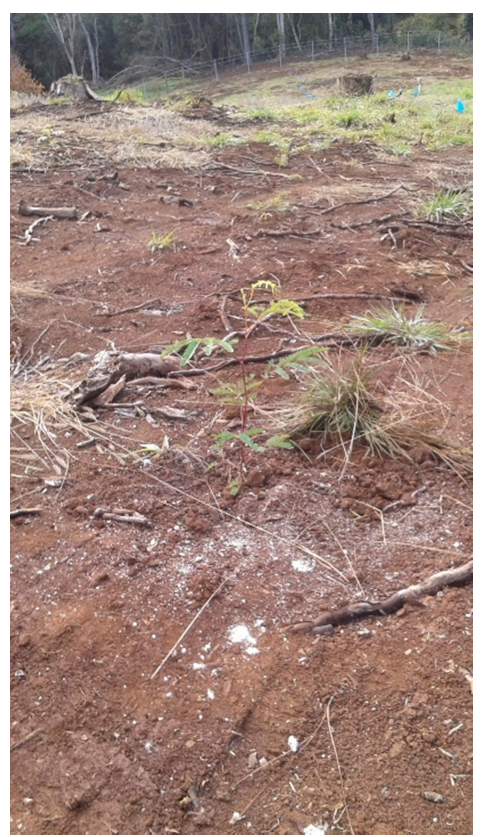

Figure A1. Recently planted koa seedling at the Kokee site.

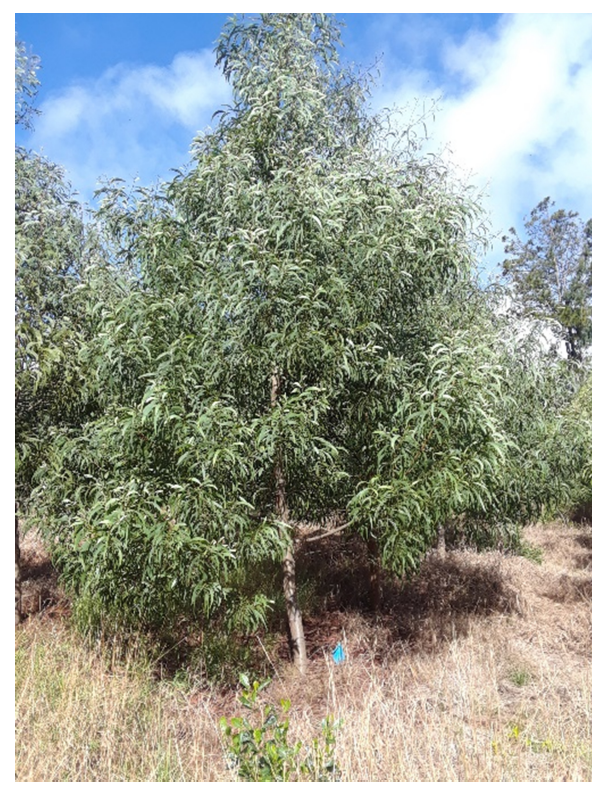

Figure A2. Koa sapling at 24 months at the Kokee site. 


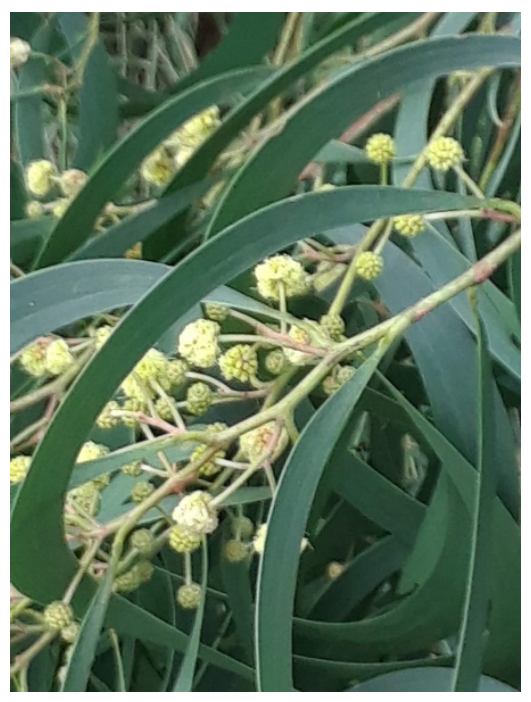

Figure A3. Koa flowering at 2 years.

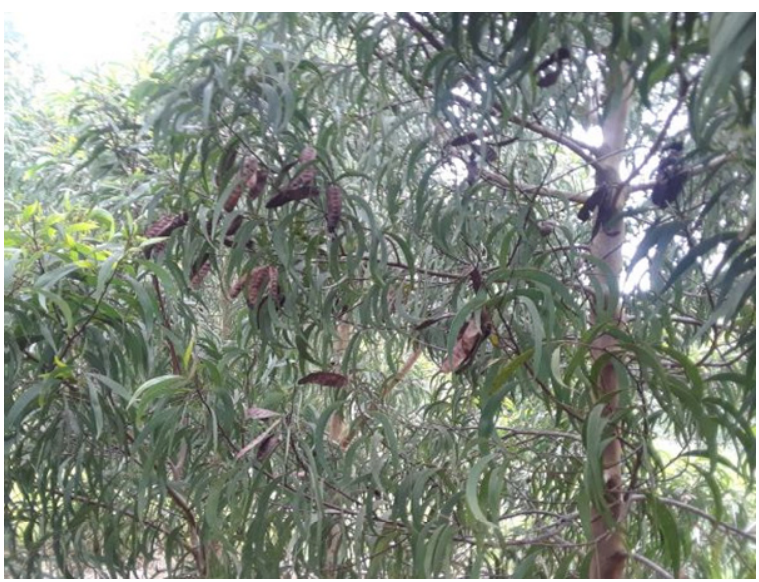

Figure A4. Mature koa seed pods ready to harvest at 30 months.

\section{References}

1. Leary, J.K.; Singleton, P.W.; Borthakur, D. Canopy nodulation of the endemic tree legume Acacia koa in the mesic forests of Hawaii. Ecology 2004, 85, 3151-3157. [CrossRef]

2. Yanagida, J.F.; Friday, J.B.; Illukpitiya, P.; Mamiit, R.J.; Edwards, Q. Economic value of Hawaii's forest industry in 2001. Econ. Issues 2004, 7, 1-3.

3. Morgenstern, M. Geographic Variation in Forest Trees: Genetic Basis and Application of Knowledge in Silviculture; UBC Press: Vancouver, BC, Canada, 2011; p. 209.

4. Patrick, J.B. Koa (Acacia Koa) Ecology and Silviculture; Department of Agriculture, Forest Service, Pacific Southwest Research Station: Albany, CA, USA, 2009.

5. Dudley, N.; Jones, T.; James, R.; Sniezko, R.; Wright, J.; Liang, C.; Gugger, P.F.; Cannon, P. Applied genetic conservation of Hawaiian Acacia koa: An eco-regional approach. In Gene Conservation of Tree Species—Banking on the Future; Gen. Tech. Rep. PNW-GTR-963; US Department of Agriculture, Forest Service, Pacific Northwest Research Station: Portland, OR, USA, 2017; pp. 78-91.

6. Wright, J.W. Introduction to Forest Genetics; Academic Press: New York, NY, USA, 1976; p. 463.

7. Zobel, B.J.; Talbert, J. Applied Forest Tree Improvement; John Wiley \& Sons: New York, NY, USA, $1984 ;$ p. 505.

8. White, T.L.; Adams, W.T.; Neale, D.B. Forest Genetics; CABI Publishing: Cambridge, MA, USA, 2007 ; p. 704.

9. Gugger, P.F.; Liang, C.T.; Sork, V.L.; Hodgskiss, P.; Wright, J.W. Applying landscape genomic tools to forest management and restoration of Hawaiian koa (Acacia koa) in a changing environment. Evol. Appl. 2018, 11, 231-242. [CrossRef] [PubMed] 
10. Dudley, N.; James, R.; Sniezko, R.; Cannon, P.; Yeh, A.; Jones, T.; Kaufmann, M. Operational disease screening program for resistance to wilt in Acacia koa in Hawaii. In Proceedings of the Fourth International Workshop on the Genetics of Host-Parasite Interactions in Forestry: Disease and Insect Resistance in Forest Trees; Gen. Tech. Rep. PSW-GTR-240; US Department of Agriculture, Forest Service, Pacific Southwest Research Station: Albany, CA, USA, 2012; pp. 286-289.

11. Anderson, R.C.; Gardner, D.E.; Daehler, C.C.; Meinzer, F.C. Dieback of Acacia koa in Hawaii: Ecological and pathological characteristics of affected stands. Forest Ecol. Manag. 2002, 162, 272-289. [CrossRef]

12. Gardner, D.E. Acacia koa seedling wilt caused by Fusarium oxysporum f. sp. koae, f.sp. nov. Phytopathology 1980, 70, 594-597. [CrossRef]

13. MacHardy, W.E.; Beckman, C.H. Vascular wilt fusaria: Infection and pathogenesis. In Fusarium: Diseases, Biology and Taxonomy; Nelson, P.E., Toussoun, T.A., Cook, R.J., Eds.; Pennsylvania State University Press: University Park, PA, USA, 1981; pp. 365-390.

14. Dudley, N.S.; Jones, T.C.; James, R.L.; Sniezko, R.A.; Cannon, P.; Borthakur, D. Applied disease screening and selection program for resistance to vascular wilt in Hawaiian Acacia koa. South. For. 2015, 77, 65-73. [CrossRef]

15. James, R.L.; Dudley, N.S.; Yeh, A. Colonization of Diseased Acacia koa Trees with Fusarium Species; Report 07-06; US Department of Agriculture, Forest Service, Forest Health Protection, Northern Region: Missoula, MT, USA, 2007; 8p.

16. Cannon, P.G.; Shelbourne, C.J.A. Forward selection plots in breeding programmes with insect-pollinated tree species. N. Z. J. For. Sci. 1993, 23, 3-9.

17. Sniezko, R.A.; Johnson, J.S.; Savin, D.P. Assessing the durability, stability, and usability of genetic resistance to a non-native fungal pathogen in two pine species. Plants People Planet 2020, 2, 57-68. [CrossRef]

18. Sniezko, R.A.; Koch, J. Breeding trees resistant to insects and diseases: Putting theory into application. Biol. Invasions 2017, 19, 3377-3400. [CrossRef]

19. Showalter, D.N.; Raffa, K.F.; Sniezko, R.A.; Herms, D.A.; Liehold, A.M.; Smith, J.A.; Bonelleo, P. Strategic Development of Tree Resistance Against Forest Pathogen and Insect Invasion in Defense-Free Space. Front Ecol. Evol. 2018, 6, 124. [CrossRef]

20. Dumroese, R.K.; Landis, T.D.; Pinto, J.R.; Haase, D.L.; Wilkinson, K.W.; Davis, A.S. Meeting forest restoration challenges: Using the target plant concept. Reforesta 2016, 1, 37-52. [CrossRef]

21. Fortini, L.B.; Kaiser, L.R.; Keith, L.M.; Price, J.; Hughes, R.F.; Jacobi, J.D.; Friday, J.B. The evolving threat of Rapid 'Ōhi ‘a Death (ROD) to Hawai 'i's native ecosystems and rare plant species. Forest Ecol. Manag. 2019, 448, 376-385. [CrossRef]

22. Pearson, H.L.; Vitousek, P.M. Stand dynamics, nitrogen accumulation, and symbiotic nitrogen fixation in regenerating stands of Acaica koa. Ecol. Appl. 2001, 11, 1381-1394. [CrossRef]

Publisher's Note: MDPI stays neutral with regard to jurisdictional claims in published maps and institutional affiliations.

(C) 2020 by the authors. Licensee MDPI, Basel, Switzerland. This article is an open access article distributed under the terms and conditions of the Creative Commons Attribution (CC BY) license (http://creativecommons.org/licenses/by/4.0/). 